\title{
The experiences of individuals with Multiple Sclerosis in the Western Cape, South Africa
}

\author{
Authors: \\ Chrisma Pretorius ${ }^{1}$ \\ Ninon Joubert ${ }^{1}$ \\ Affiliations: \\ ${ }^{1}$ Department of Psychology, \\ Stellenbosch University, \\ South Africa \\ Correspondence to: \\ Chrisma Pretorius \\ Email: \\ chrismapretorius@sun.ac.za \\ Postal address: \\ Private Bag X1, Matieland, \\ South Africa \\ Dates: \\ Received: 30 May 2013 \\ Accepted: 15 Oct. 2013 \\ Published: 23 Apr. 2014 \\ How to cite this article: \\ Pretorius, C. \& Joubert, N. \\ 2014, 'The experiences of \\ individuals with Multiple \\ Sclerosis in the Western \\ Cape, South Africa', Health \\ SA Gesondheid 19(1), Art. \\ \#756, 12 pages. http:// \\ dx.doi.org/10.4102/hsag. \\ v19i1.756

\section{Copyright:} \\ (C) 2014. The Authors. \\ Licensee: AOSIS \\ OpenJournals. This work \\ is licensed under the \\ Creative Commons \\ Attribution License.
}

Background: Multiple Sclerosis (MS) is a debilitating and degenerative lifelong neurological disease that seems to be growing increasingly more prevalent in South Africa.

Objectives: The aim of this qualitative study was to explore the personal experiences of individuals with MS in the South African context. The focus of this study was on the challenges faced by individuals with MS, as well as the resources that help them to cope with this debilitating, neurological condition.

Method: Thematic analysis was used to explore the semi-structured interviews that were conducted with ten individuals with MS.

Results: Several themes emerged that related to the participants' experiences of living with MS. These themes included several challenges faced by the participants on a daily basis, such as the process of being diagnosed, daily life, invisible illness and medical aid schemes. Numerous resources that help these individuals to cope with MS also emerged from the data analysis and consisted of social support, mobility aids, religion and knowledge about MS.

Conclusion: It is evident from the findings of this study that although individuals living with MS, which is a debilitating neurological condition, face several challenges on a daily basis, they often have several resources that help them to cope effectively with this condition. The findings of this study regarding knowledge of the challenges faced and the resources utilised by individuals with MS will hopefully create awareness of the disease and contribute to and inform the design and implementation of interventions for such individuals.

Agtergrond: Veelvuldige Sklerose (VS) is ' $n$ aftakelende en degerenatiewe lewenslange neurologiese toestand wat blyk of dit toenemend meer algemeen in Suid-Afrika voorkom.

Objektief: Die doel van hierdie kwalitatiewe studie was om die persoonlike ervarings van individue met VS binne die Suid-Afrikaanse konteks te ondersoek. Die fokus van hierdie studie was op die uitdagings wat individue met VS in die gesig staar, sowel as die hulpbronne wat hulle help met die hantering van hierdie ernstige neurologiese toestand.

Metode: Tematiese analise is gebruik om die semi-gestruktureerde onderhoude te ondersoek, wat gevoer is met tien individue met VS.

Resultate: Verskeie temas wat verband hou met die deelnemers se ervarings van ' $n$ lewe met VS het na vore gekom. Hierdie temas het verskeie uitdagings ingesluit wat die deelnemers op 'n daaglikse basis in die gesig staar, soos die proses om korrek gediagnoseer te word, daaglikse lewe, onsigbare siekte en mediese fonds skemas. ' $n$ Aantal hulpbronne wat hierdie individue help om VS te hanteer het ook na vore gekom en bestaan uit sosiale ondersteuning, mobiliteit hulpmiddels, geloof en kennis oor VS.

Gevolgtrekking: Dit is duidelik uit die bevindinge dat alhoewel individue wat lewe met VS, wat 'n ernstige neurologiese toestand is, verskeie uitdaging op ' $n$ daaglikse basis in die gesig staar, hulle beskik oor verskeie hulpbronne wat hulle help om hierdie toestand effektief te hanteer. Die bevindinge van hierdie studie rakende kennis van die uitdagings wat hierdie individue in die gesig staar en die hulpbronne wat individue met VS gebruik sal hopelik ' $n$ bewustheid skep en bydra tot die ontwerp en implimentering van intervensies vir sulke individue.

\section{Introduction}

Multiple Sclerosis (MS) is a debilitating, chronic and degenerative neurological disease where demyelination of the central nervous system (CNS) occurs and causes lesions in the axons of the nerves (McCabe 2005; Mohr et al. 1999). MS is a serious disease which occurs worldwide. The prevalence and incidence rates worldwide for MS are estimated at 30 per 100000 and 2.5 per 100000 respectively (Dua \& Rompani 2008). CBC news (2012) puts the prevalence rate for South 
Africa at 32 per 100 000. According to Modi et al. (2008), who conducted a quantitative study on MS in South Africa, South Africa is a medium-frequency region (5-30 per 100 000). It is evident from these statistics that MS is not only a worldwide problem, but also seems to be relatively prevalent in South Africa specifically. The disease is found more commonly amongst women and generally appears between the ages of 20 to 40, which is the period when individuals settle into their careers and families (McCabe 2005). Bhigjee, Moodley and Ramkissoon (2007) reported a similar onset age (between 31 and 35 years) in their study which was conducted in KwaZulu Natal, South Africa, using patients' chart information. Similarly, Modi et al. (2008) looked at all the South African provinces and reported that two-thirds of individuals with MS had an onset between the ages of 20-40 years old. These statistics suggest that MS is considered to be a public health concern and is therefore a research area worth investigating.

Although the precise causes of MS are still unknown, many studies have been conducted in order to investigate probable causes (Courtney et al. 2009; Cross, Cross \& Piccio 2012; Maghzi et al. 2011; Rumrill 2009; Young 2011). Genetic, environmental and immunologic factors have been linked to the development of MS (Courtney et al. 2009; Cross et al. 2012; Rumrill 2009). The presence of DR21501B1, the human lymphocyte antigen allele, is linked to a higher susceptibility chance of triggering MS (Courtney et al. 2009; Cross et al. 2012; Maghzi et al. 2011; Rumrill 2009; Young 2011). There is also a theory that environmental triggers, such as low levels of Vitamin D (as seen in the northern hemisphere), can activate the development of MS in genetically-predisposed individuals (Courtney et al. 2009; Maghzi et al. 2011; Rumrill 2009).

There are four subtypes of multiple sclerosis, namely relapsing/remitting, secondary, primary progressive and progressive relapsing (Courtney et al. 2009). Relapsing/ remitting MS (RRMS) is usually the first form of diagnosis in $80 \%$ of individuals with MS (Reipert 2004). The patient can experience relapses in succession and then pass into a complete or semi-state of remission (Reipert 2004). The second subtype is primary progressive MS (PPMS), during which symptoms escalate gradually and physical capabilities decline, with a prevalence of $10 \%-20 \%$ in individuals with MS (Reipert 2004). Secondary progressive MS (SPMS) develops in $50 \%$ of previously RRMS-diagnosed patients within 10 years (Reipert 2004). A characteristic of this type is the constant development of medical neurological damage in addition to or without greater relapses and with short periods of remission (Reipert 2004). The last type, also the rarest, is progressive relapsing MS (PRMS), where dysfunction progresses steadily, followed by the development of genuine exacerbations (periods where symptoms worsen and the individuals may need hospitalisation) (Courtney et al. 2009). Similar findings and/or statistics were reported by Modi et al. (2008) in their South African study of MS. The study found that, of their 430 participants, $46 \%$ were diagnosed with RRMS, $13 \%$ with SPMS, $12 \%$ with PPMS, $12 \%$ with PRMS and $17 \%$ had been diagnosed with MS but were not sure of their type (Modi et al. 2008).
The symptoms that individuals with MS present with can vary enormously. It can be present in different areas of the body and the degree of the severity of the symptoms can also vary from person to person (Reipert 2004). Individuals with MS can present with sensory disturbances, diplopia, unilateral optic neuritis, Lhermitte's sign, clumsiness, limb weakness and walking ataxia. They may also report bladder, bowel and sexual dysfunction problems (DasGupta \& Fowler 2003; Demirkiran et al. 2006). Not only have these symptoms been noted in people living with MS, but they have also been reported to be the most distressing symptoms of this degenerative neurological disease (DasGupta \& Fowler 2003).

People with MS have also reported that their symptoms worsen as the environmental temperature rises (Grahn, Murray \& Heller 2008; Romberg et al. 2012; Saaroni et al. 2010; Tataru et al. 2006). Aggravated symptoms and signs include nystagmus, muscle weakness, visual dysfunction and abnormal reflexes (Grahn et al. 2008; Romberg et al. 2012). It has also been found that the core body temperature of individuals with MS is more sensitive to exercise and exposure to environmental heat (Marino 2009). A higher core body temperature is likely to lead to increased heat sensitivity and results in symptomatic fatigue, although not all the mechanisms are understood clearly (Marino 2009). Fatigue is one of the most predominant outcomes of this neurodegenerative disease (Marino 2009). It has been reported that as many as $78 \%$ of individuals living with MS report fatigue on a daily basis (Blaney \& Lowe-Strong 2009). Fatigue can be a significant problem as it shortens the time that people with MS can spend on their daily activities, such as recreational pursuits and employment, both of which have potential for further opportunities, health benefits and enjoyment (Marino 2009).

The diagnosis of MS is a complicated and lengthy process. To date, there is no single laboratory test and there are no physical findings or specific symptoms that can lead to a definite diagnosis of MS (Reipert 2004). The diagnostic criteria for an MS diagnosis were established by McDonald et al. (2001). These criteria, which are known as the gold standard for diagnosing MS, were revised in 2005 and again in 2010 and are now known as The Revised McDonald Criteria (Robinson 2011). Magnetic Resonance Imaging (MRI) and cerebrospinal fluid (CSF) analysis are advancements in medicine which improve sensitivity for the detection of MS as well as facilitating an earlier diagnosis (Courtney et al. 2009).

Although there is no cure for MS, there are drugs to slow down the development of the disease, as well as medication to treat some of the associated symptoms (Reipert 2004). Three groups of medication have been approved by the Food and Drug Administration (FDA) for the treatment of MS, namely interferon-beta (IFN), Glatiramer acetate and Mitoxantrone (Reipert 2004). This medication is injected subcutaneously or intravenously (Reipert 2004). The first oral treatment for MS, Fingolimod, was approved by the Food and Drug Administration during September 2010 (Jeffrey 2010). In 
addition to medication, some forms of psychotherapy were also found to be effective in alleviating some of the signs and symptoms that individuals living with MS present with. Cognitive therapy and therapeutic approaches that make use of supportive strategies in particular, were found to be effective. In the South African study on MS by Modi et al. (2008), the most-used treatments in 2008 were a low dose of naltrexone $(1 \%)$, imuran $(2 \%)$, alternative homeopathic medication $(15 \%)$, interferon $(22 \%)$, methotrexate $(30 \%)$ and no medication (32\%) amongst 430 participants with MS.

\section{Living with multiple sclerosis}

Individuals suffering from MS face several challenges. Malcomson, Lowe-Strong and Dunwoody (2008) investigated the experience of living with MS in Ireland and found that the experience of this chronic illness starts even before diagnosis. Physical changes such as sensory disturbances generally prompt individuals to go to their doctors. This is usually how the journey to a diagnosis of MS starts. This process is generally filled with uncertainty, stress and fear (Malcomson et al. 2008). Individuals suffering from MS also describe the process of diagnosis as being lengthy and frustrating at times (Malcomson et al. 2008). Eventually, when the diagnosis is confirmed, MS sufferers experience the conversation about the diagnosis as being unhelpful because it is often abrupt and doctors are insensitive and still seem to be vague about the diagnosis (Malcomson et al. 2008). This results in MS patients feeling unsupported (Malcomson et al. 2008).

Individuals suffering from MS report that it becomes increasingly difficult to maintain a social life as their MS symptoms progress because they have to consider things such as transport to and toilet facilities at the meeting place (Malcomson et al. 2008; Mohr et al. 1999). Fatigue is experienced by most MS patients and is listed as the most frequent challenge (Courtney et al. 2009). Fatigue has also been linked to communication problems such as slurring, dysarthria, speech difficulties and word-retrieval problems, as well as slower information processing (Blaney \& LoweStrong 2009; Diamond et al. 2007).

Moreover, individuals living with MS also face problems with regard to their personal lives. For example, women suffering from MS face the challenge of decisions about having children, especially when considering their ability to care for a baby; these challenges include fatigue, financial concerns and support, societal attitudes and concerns about passing on the genetic predisposition to developing MS (Payne \& McPherson 2010; Prunty et al. 2008). Another facet of this multidimensional experience of MS is stress, possibly relating to the onset, progression or exacerbation of symptoms; the possibility of having to move houses because stairs or a large property might become impractical in light of MS-related physical impairments; the loss of employment; and the challenges of practical tasks such as grocery shopping and looking after the family (Malcomson et al. 2008; Riise et al. 2011). Often, individuals living with MS also seem to experience psychological distress. Depression, anxiety and low self-esteem seem to be particularly prevalent amongst individuals with MS (McCabe 2005; Mohr et al. 1999).

Although individuals living with MS face a variety of challenges, it is also evident that there are several resources that help them to cope with this condition. Social support seems to be an important resource in helping people to cope whilst living with MS (Goretti et al. 2009; Malcomson et al. 2008; Mohr et al. 1999). Support groups have been identified as being a particularly important source of social support because this provides them with the opportunity to meet other people also living with MS and to share their experiences and advice (Malcomson et al. 2008). A positive attitude has also been identified as a key resource (Malcomson et al. 2008). Individuals suffering from MS typically try to remain positive, refrain from blaming others for their disease, practice positive self-talk and instil a fighting attitude within themselves (Malcomson et al. 2007). Religion has also been noted as providing support for individuals with MS, particularly for women (Goretti et al. 2009; Twork et al. 2007). According to Twork et al. (2007), religiosity is mainly associated with positive attitudes and health outcomes for individuals with MS. Other forms of stress relief include yoga, aromatherapy and relaxation sessions (Malcomson et al. 2008). Malcomson et al. (2008) report that MS patients find it necessary and helpful to stay up to date with MS information about alternative treatments. Individuals with MS also reported that a proactive outlook in terms of personal research into their disease, such as changing doctors and realising that they still have choices, seems to help them (Malcomson et al. 2008).

Various energy conservation strategies have been identified for the relief of fatigue in particular (Matuska, Mathiowetz \& Finlayson 2007). The most effective energy conservation strategies, according to Matuska et al. (2007), include resting during prolonged activities that last longer than 30 minutes and delegating tasks to family members, such as carrying or moving objects and cooking (Matuska et al. 2007). In addition, special cooling vests with tubing that is filled with a coolant have been designed in order to help individuals with MS to cope with the heat (Grahn et al. 2008; Kraft 2010). The researchers found that these vests help heat-sensitive individuals to reduce symptoms that are triggered by heat, such as fatigue, and also help people with MS to improve their coordination and balance, increasing physical activity (Kraft 2010).

It is evident from the literature that MS is a debilitating lifelong disease which includes a wide array of symptoms. It is also evident that the prevalence rate of MS worldwide is on the rise, establishing it as a growing concern (Modi et al. 2008). Within the South African context, there is a need for research on this topic, as MS affects 32 per 100000 individuals and it is thus a common disease in the country (CBC News 2012). A few international studies have examined the experiences of individuals with MS, but no studies of this nature have been conducted in South Africa. South African studies of MS are focused mainly on the epidemiological nature of the 
disease (Bhigjee et al. 2007). It can be expected that all people suffering from MS all over the world will display similar symptoms, because it is primarily a medical condition. However, it is possible that cultural and/or geographic factors may influence the experiences of individuals living with MS, to a certain extent. These factors may differ from country to country and could include issues such as the quality of services and support rendered by the health services, as well as the type of support given by family, friends and the community in general. The availability of social support services, such as support groups organised by a dedicated organisation and the availability and efficiency of medical support services such as the medical aid schemes and mobility aids, are further examples of factors that may differ from country to country. With this in mind, the aim of this study was to explore the unique experiences of individuals living with MS within the South African context, with a specific focus on the challenges faced by individuals living with MS and the support and/or resources that help these individuals cope with their condition.

\section{Research method and design}

This study was an exploratory, qualitative study. A qualitative approach was chosen as the most appropriate methodology to explore the experiences of individuals living with MS, because it enables the researcher to make an indepth inquiry and to incorporate complex and rich insights from individuals' personal experiences (Coenen et al. 2011).

\section{Participants and procedure}

The Chairperson of the Western Cape MS Society assisted with the identification of potential participants. Crabtree and Miller (1999) suggest that five to eight participants are sufficient to provide rich information for qualitative research. For this reason, the participants consisted of a convenience sample of 10 individuals living with MS. The sample consisted of seven women $(70 \%)$ and three men $(30 \%)$, with ages ranging between 38 and 71 years (mean = 52) (refer to Table 1). The time since diagnosis ranged between six months and 40 years (mean $=12$ years). Four participants were diagnosed with RRMS, one with PPMS and five with SPMS, although two individuals with SPMS reported that their MS was RRMS at onset. MS is a very heterogeneous medical condition and the time since diagnosis as well as the type of MS varies significantly in this population. We therefore included the experiences of individuals with MS from a heterogeneous group, to attempt to achieve a more representative picture of the experiences of individuals living with MS. In addition, the main aim of this exploratory study was to form a picture of the experiences of individuals who live with MS in general. The focus was not on a specific time since diagnosis or on a specific type of MS. Because this study is the first of its nature in South Africa, the results of this study could serve as a broad baseline from which future, more focused, studies would hopefully emerge.

After informed consent was obtained, an individual, semistructured interview of between 60 and 90 minutes was conducted with each participant. The semi-structured interviews were guided by the following questions:

- Tell me about the process of getting to a diagnosis of MS.

- Tell me about your experience of living with MS.

- What makes it difficult for you to cope with MS?

- What are the factors and/or resources that make it easier for you to cope with MS?

Each interview was audio recorded, after which the interview was transcribed verbatim for the process of data analysis.

\section{Analysis}

Thematic analysis was used to analyse the data (Braun \& Clarke 2006). As a first step in the data analysis, the primary researcher familiarised herself with the data through the transcription process by listening to the interviews as well as reading through the data several times, whilst thinking about possible themes (Braun \& Clarke 2006). Thereafter, initial codes for the transcribed information were generated, which involved the manual coding of interesting features of the entire dataset. This step was necessary in order to organise the data into meaningful groups (Braun \& Clarke 2006). In the next step, themes were identified by organising possible codes into themes. Thereafter, the themes in the document were defined and named in order to refine each theme (Braun \& Clarke 2006). Finally, a report was produced with all the major and subthemes. The report was substantiated with compelling, vivid extract examples from the transcripts (Braun \& Clarke 2006). Direct quotations from the interviews with the participants are used in order to illustrate themes and categories.

TABLE 1: Demographic details of participants.

\begin{tabular}{|c|c|c|c|c|c|c|}
\hline Participant code & Age (years) & Race & Type of MS & Language & Year since diagnosis & Support group \\
\hline F1 & 61 & White people & $\mathrm{RR}$ & English & 5 & Yes \\
\hline $\mathrm{F} 2$ & 61 & White people & SP & German & 3 & Yes \\
\hline F3 & 28 & Mixed race & $\mathrm{RR}$ & English & 0.6 & No \\
\hline M4 & 71 & White people & SP & Afrikaans & 40 & No \\
\hline M5 & 71 & White people & PP & English & 24 & Yes \\
\hline F6 & 68 & White people & $\mathrm{RR}$ & English & 12 & Yes \\
\hline F7 & 57 & White people & $\mathrm{RR}$ & English & 12 & Yes \\
\hline F8 & 38 & Mixed race & $\mathrm{SP}$ & English & 8 & Yes \\
\hline M9 & 41 & White people & SP & English & 6 & No \\
\hline $\mathrm{F} 10$ & 41 & White people & SP & Afrikaans & 12 & Yes \\
\hline
\end{tabular}

Participant code: F, Female; M, Male; MS, multiple sclerosis; Type of MS: RR, Relapse Remitting MS; SP, Secondary Progressive MS; PP, Primary Progressive MS. 


\section{Ethical considerations}

Before the commencement of this study, ethical approval was applied for through the Health Research Ethics Committee at the Faculty of Health Sciences at Tygerberg Hospital. Ethical approval was received with Ethics Reference number S12/06/154. When invited to participate in this research, the nature and the relevance of the research were explained to all the participants. They were informed that their participation was completely voluntary and that they had the right to withdraw from the study at any stage of the process without any negative consequences. The participants were also informed that they would incur no additional expenses through participation in this study. Informed consent, which included permission to record the interviews, was required from all of the participants before the data collection commenced. The participants' confidentiality was protected by assigning them a participant number when the data was analysed. Only the research team had access to the personal details of the participants. The audio-recorded interviews were transcribed and are currently kept safe and secure in a locked drawer in the researcher's office. The only foreseeable risk was that participants might experience emotional distress or discomfort during the interview process due to the personal nature of the information being disclosed. The research team did not foresee that any participants would experience distress to the extent that they would need to be referred for counselling. However, if it did occur that a participant required counselling, there was a procedure in place to refer them to an appropriate healthcare professional.

\section{Trustworthiness}

Lincoln and Guba (1985) posit that trustworthiness of a research study is important when it comes to evaluating its worth. According to Lincoln and Guba (1985), one way to enhance dependability is when the researcher makes use of colleagues and methodological experts (peer examination) to check the research plan and implementation. It is standard procedure in the researchers' department that at least two colleagues, usually with methodological expertise in the particular field, review the research plan before the implementation thereof. Credibility refers to accurate descriptions and interpretations of the participants' views and experiences by the researcher, whilst confirmability refers to the extent to which the findings can be confirmed by others (Lincoln \& Guba 1985). The credibility and confirmability of this study's findings was enhanced by the investigators' reflective diaries and triangulation of data. Reflective diaries were kept by the primary researcher and the content was discussed with two other team members, one with expertise in qualitative research and an experienced MS researcher. In this way, reflexivity was enhanced because personal biases, attitudes and perceptions were discussed and brought into the open.

Triangulation of investigators was also used and this occurs in a study where a research team, rather than a single researcher, is used. In addition to the primary researcher, the other two members of the research team conducted the process of data analysis independently, as described in the previous section. The themes that emerged were then compared and differences in interpretation were resolved through discussion. The final version of the findings represents the consensus reached by the researchers. With regard to transferability, that is, the extent to which the results of the study can be generalised outside the context of the study or with other study members (Lincoln \& Guba 1985), thick descriptions of the participants and the research setting and context were provided in order to allow others to assess how transferable the findings are. According to Lincoln and Guba (1985), it is the researcher's obligation to provide a sufficient database to allow conclusions about transferability to be made by others; it is not the responsibility of the researcher to deliver an index of transferability in qualitative research.

\section{Results}

It emerged from the semi-structured individual interviews with the participants that, whilst their situations, the type of MS and the progression of the condition varied from individual to individual, a number of common themes were apparent from their experiences. The main themes and the related subthemes that were identified through thematic analysis are presented in Table 2. It is important to note that themes are not presented and discussed in any particular sequence of importance. The two main themes were the challenges faced by individuals suffering from MS and the resources which help MS patients to cope with this debilitating, neurological condition.

\section{Challenges}

The first main theme that emerged from the data analysis was that the participants in this study faced several challenges. The subthemes related to the challenges that these individuals faced are: diagnosis, daily life, invisible illness and medical aid schemes.

\section{Diagnosis}

In general, it seems that the participants experienced the period of time over which medical professionals were involved with them in order to reach a diagnosis of MS as a challenging process. Participants reported experiencing a range of symptoms that interrupted their activities of daily living and prompted them to seek medical assistance before an official diagnosis of MS was made. The following extracts illustrate the impact of the initial MS symptoms on the runof-the-mill routine of the participants.

TABLE 2: The main themes and their related subthemes that were identified through thematic analysis.

\begin{tabular}{ll}
\hline Main theme & Subtheme \\
\hline Challenges & - Diagnosis \\
& - Daily life \\
& - Invisible illness \\
& Medical aid schemes \\
Resources & Social support \\
& Mobility aids \\
& - Religion \\
& Knowledge about Multiple Sclerosis \\
\hline
\end{tabular}


'I said you know I'm tired of doing everything twice. I said I'll bend down to pick up the washing and I'll pick it up and as I'm going to put it on the line I'll drop it, or I'll reach for something and I'll have to reach twice. So he worked out that my cognitive things were not as they should be ... It started with cognitive. And, and fatigue.' (P1, Female, 61 years)

'So I couldn't drive for a few weeks and I couldn't walk without holding onto the furniture and the walls.' (P7, Female, 57 years)

Random and seemingly unrelated symptoms such as optic neuritis, a loss of movement and feeling in hands and feet, spasticity, sensations of pins and needles, problems with balance, a loss of vision and blackouts were also reported.

The process of reaching a diagnosis of MS was a distressing time and it formed an important part of the participants' journeys with this debilitating condition. For most of the individuals it was a lengthy and stressful process. One participant reported:

'Uhm, well I had to wait five years for the diagnosis because it didn't show up on the MRI. It was only when I had my third attack that it finally showed up.' (P1, Female, 61 years)

The diagnostic phase was generally filled with feelings of anxiety, frustration and uncertainty. The following extract captures the some of these emotions:

'I asked three doctors to send me for a MRI scan; they all asked me why I want to go for a MRI. I said: "Because I know my body, I know there is something wrong". They told me I do not need that, they laughed at me.' ( $\mathrm{P} 8$, Female, 38 years)

The detailed descriptions and vivid recollections on the part of the participants about when they were confronted with an official diagnosis of MS, illustrate the enormous impact of this event. It was clear that this was an emotionally-challenging time for the majority of the participants $(n=9)$ and their reaction to the diagnosis ranged from shock to devastation. One participant described it as:

'a bomb that could not be absorbed.' (P9, Male, 41 years)

Whilst another responded in the following way:

'I couldn't quite believe it. I was pretty devastated.' (P6, Female, 68 years)

Whereas most participants were overwhelmed by the diagnosis of MS, one participant reported feelings of relief. This is illustrated in the following extract:

'I was happy, I was happy ... finally to know what is wrong with me because that worried me most.' (P2, Female, 61 years)

Although positive experiences like these were in the minority, it could potentially be seen as a resource, because after eventually getting a name for their symptoms, they could move forward and start to learn how to cope and live with MS.

The experiences of the participants with healthcare professionals that were involved during the process of diagnosis also emerged as an important theme. Unfortunately, most of the participants had previous negative experiences with healthcare professionals and expressed their dissatisfaction during the interviews. Some of the participants reported that the doctors were unsympathetic and they were described as having limited time for the patients, rushing off in order to see the next patient. One of the participants described her experience as follows:

'Unfortunately the system being as it is, you've got like three or four or five minutes maximum to see a patient ... uhm ... so, you've got it; this is what we can do for you. You know we are here for you, deal with it, but sorry I've got to see the next patient. They weren't, unfeeling, but just, you know, I'm sorry ... rushed.' (P7, Female, 57 years)

The majority of the participants reported that, at the time of their diagnosis, little to no information was offered to them by the healthcare professionals regarding how to cope with MS or how to adjust their daily lifestyle. The feedback by the doctors was generally described as insensitive:

'There is no cure; you just have to get on with it. Cortisone is your friend. Uhm ... that's about it.' (P5, Male, 71 years)

\section{Daily life}

The participants reported a number of symptoms that they found challenging in their day-to-day functioning. The following extract about life before MS from one of the participant's perspectives summarise many of the changes and adaptations that several of the participants of this study had to make:

'It was a lot, I don't want to use the word fuller, busier, a lot more hectic, we were like, you know, out for lunch, out for dinner, you know, family, this, that, you know, overseas and travelling, you know work ... Like before, it sounds awful, but we didn't really worry about anything ... Now, it's like this constant thing at the back of your head, it's always there and it's becoming almost second nature now.' (P3, Female, 28 years)

This section deals with some of the prominent factors that have an impact on the daily living of, and limit the functioning of, the participants of this study. These factors include impaired mobility, bladder and bowel problems, sexual problems and problems with eyesight, fatigue and heat.

Because of their MS, the majority of the participants seemed to experience problems with walking and moving around. The following two extracts illustrate the difficulty that the participants have to face:

'... my left leg is also the lazy one, it's not the one I can get up so easy - when I walk ... sometimes I just pull it with me.' (P2, Female, 61 years)

'Walking is a problem so even if I go on holiday I'm limited ... I, I, I can't walk on, on, on ground that isn't 100\% level.' ( P6, Female, 68 years)

It was evident from the analysis that all the participants had to make major adjustments to their lifestyle because of their difficulties with mobility. Some of these adjustments included daily assistance with personal care or depending on family and friends to get around, because they cannot drive anymore. 
A number of participants reported bladder dysfunction and/or having no or insufficient voluntary control over bowel movements as being challenging. Not only were these difficulties described as a physical problem, but they were also said to be very humiliating. This sentiment is captured by the following statement:

'I think, for me the worst is my bladder. It is the biggest drama in my life ... but a bladder thing is an embarrassing thing.' (P10, Female, 41 years)

Another challenge that emerged during the interviews that has a major impact on the daily functioning of the participants was sexual difficulties. One participant described her lack of sexual activity owing to the disorder due to a loss of libido. She stated:

'My sexual life is also not existing anymore yes [ja] ... I remember there was something and it was nice, but it is okay now - because I don't feel it anymore.' (P2, Female, 61 years)

Sexual problems not only affect the participants, but also have an effect on their partners. According to several participants, these problems sometimes lead to challenges in their relationships.

Visual problems were another major challenge for the research participants. Optic neuritis was reported by one participant and a number of participants reported problems with depth perception. Another problem was partial blindness, as is illustrated by the following excerpt:

'I lost all my vision in my left eye ... came back slightly but never came back completely.' (P6, Female, 68 years)

It was evident that visual problems can manifest in many different ways. Some of the problems that they encounter because of these difficulties include the inability to drive anymore and the subsequent dependence on family and friends for transport. Some of the participants need assistance with personal care and daily activities. Fatigue was another prominent symptom that has an enormous impact on the daily functioning of the participants of this study. This was mentioned by most of the participants as being a challenge, clearly indicating that fatigue is a major problem amongst individuals with MS. Participants explained that fatigue can occur at any time, even after you have had a good night's rest, as described in the following quotation:

\footnotetext{
'... the fatigue part is also awful because it is really that you could have done absolutely nothing and the next day you feel that you can't even get yourself out of bed.' (P8, Female, 38 years)
}

The fatigue associated with MS is therefore experienced as being both uncontrollable and unpredictable. One participant mentioned that this is frustrating because you can never plan too far ahead. It was evident that fatigue contributes to the adjustments that they have to make in their daily lives, because they are often forced to pace themselves according to the level of fatigue that they are experiencing. Fatigue often seems to limit the daily activities of MS patients significantly. The heat, especially during the summer months, seems to have a tremendous effect on the daily lives of the MS sufferers. Some of the participants described some of the lengths to which they would go to dissipate the heat, indicating that it interferes extensively with their daily lives. This is described in the quotation below:

'Oh and the heat ... I'd have like five cold showers in a row because I'd get out of the shower get downstairs and be boiling again, OK, so I'm back upstairs back into a cold shower.' (P3, Female, 28 years)

\section{Invisible illness}

A further major challenge was that many of the participants felt frustrated that other people could not see that they are ill. According to the participants, the general public are not well informed about the nature of MS. The participants seem to feel that people will, for example, easily have empathy with someone with cancer who is wearing a scarf to cover their loss of hair, because their illness is noticeable. However, people in general do not seem to have as much empathy for MS sufferers, because often the symptoms that individuals with MS experience, such as fatigue, are not observable. One participant stated:

'But if you have MS, then you look normal and you look OK and people cannot understand ... so they have MS, but it is totally invisible. You cannot see it. So then you are going to think that they look ok so what are they complaining about?' (P10, Female, 41 years)

This 'invisible' illness was also evident in the participants' workplace. Individuals with MS felt that the people they worked with could not see that they were ill and, as a result, treated them as if they were not ill. Their colleagues would comment that individuals with MS were pretending to be ill. As a result, some participants were anxious about losing their jobs.

\section{Medical aid schemes}

The majority of the participants who have access to a medical aid scheme $(n=6)$, reported challenges associated with getting the medical aid to pay for chronic medicine. Several participants have to pay cash for their medication, even though they have access to a medical aid scheme, because the medical aid scheme has a number of restrictions and limitations with regard to MS. For example, a patient is required to experience a prescribed number of MS relapses within a certain period of time before a medical aid scheme will consider paying for chronic medication. There are also certain age restrictions. The participants expressed their frustration with these restrictions and limitations, because MS affects every individual in a different way and they feel that each case should be considered on an individual basis:

'Then the fight with the medical aid started ... they didn't want to approve it ... because there is this thing that you haven't had two relapses within two years and you have to get intravenous cortisone twice. Pills do not count ... bla bla bla ...' (P10, Female, 41 years) 
On the other hand, the participants who do not have access to a medical aid scheme $(n=4)$ stated how expensive MS becomes if you have to pay cash for all the medication that you need. Some of the participants mentioned that they can't afford the medication, because the medication on its own is more than their monthly income. Alternatively, these participants have access to state hospitals where they can get some of their medication. However, state hospitals do not always have available all the medication they need, as one participant reported:

'I just hope that the state will get certain of the drugs that the people on medical aid have access to ... that by then the state will also be able to give us state patients access to it as well.' (P5, Male, 71 years)

\section{Resources}

The second main theme that was identified was resources which helped the participants to cope with MS. Several subthemes emerged from the interviews, namely: social support, mobility aids, religion and knowledge about MS.

\section{Social support}

The participants reported receiving support from various sources, the most important being support from family and friends and from an MS support group.

For individuals who were married, their partners were described as being a significant form of support. Not only were spouses important, but other family members, such as children and parents as well as friends, were equally important for some participants. This is evident in the following quotations:

'I think it was easy for me as I have an amazing family. So, so supportive ...' (P7, Female, 57 years)

'I've got a lovely group of friends. I mean they will usually phone me because I'll sit and sit and think, OK, well I'll give Susie [pseudonym] a ring just now and then she phones me before ... “I'm coming to fetch you tonight".' (P6, Female, 68 years)

In addition to the support of family and friends, participants also seem to benefit from the support that they receive from MS support groups. Most of the participants are part of either a face-to-face MS support group, organised by the Western Cape Multiple Sclerosis Society of South Africa, or of the online MS Facebook support group. It seems as though most of the participants find these support groups to be very helpful and several of the participants referred to this as a major resource. This is because of the information network amongst members which allows them to share useful tips, knowledge and support. It was evident that the participants found the online MS Facebook support group particularly helpful as it provides them with the opportunity to get information, ask questions, express their emotions anonymously in the comfort of their own homes and get support from individuals with the same condition:

'Uhm ... well on Facebook every day. Continuously and constantly on Facebook ... es, yes, ja, ja. It definitely helps ... Every day. I use it every single day.' (P1, Female, 61 years)

\section{Mobility aids}

Whilst problems with mobility were evident as a major challenge in this study, almost all of the participants used some sort of mobility aid, ranging from crutches and walking frames, to wheelchairs and hoisting mechanisms to get out of the bed and into the bath. One participant reported finding railings in the shower and the bath helpful, whilst another participant managed to create more mobility for himself with the installation of a stair lift. The mobility aids were described as being a useful resource as they helped the participants to be more mobile and independent than they would have been without these devices. The extracts below show how the participants cannot really imagine their lives without these mobility aids:

'I always keep a crutch in the car.' (P7, Female, 57 years)

'We've got a hoist in the car so I can get into the car ... there's also a hoist in the bathroom ... I get around with a wheelchair.' (P5, Male, 71 years)

\section{Religion}

Some of the participants reported religion as being another resource that helped them to cope with their MS. Their religion helped to make the acceptance of their condition easier; it gave them a purpose in life and gave them hope of healing. These sentiments are conveyed in the following extracts:

'Constantly - I pray every day ... I understand I have MS and there is no cure, but I know God is allowing me to go through this and one day He will surprise me and I in turn will surprise everyone else.' (P8, Female, 38 years)

'My faith is very strong ... I only live for Him.' (P4, Male, 71 years)

\section{Knowledge about Multiple Sclerosis}

In addition to social support, mobility aids and religion, gathering information about MS was also deemed to be an important resource for participants. Some of the participants reported that the MS support groups, whether a face-to-face support group or the online MS Facebook support group, are valuable sources with regard to gathering information about MS. One participant mentioned that she finds reading autobiographies of people with MS helpful and referred to it as 'bibliotherapy'. The internet was also mentioned as an important resource for gathering information about MS. Other participants compiled their own information about MS and this was described as being helpful:

'When I could read at the time I used to read about MS because my mom's younger brother worked at a medical place and he gave it to me and made copies for me ... Yes. It was very helpful.' (P8, Female, 38 years)

\section{Discussion}

Overall, the results confirm studies (Barker-Collo, Cartwright \& Read 2006; Malcomson et al. 2008) saying that MS is a 
debilitating neurological condition and that individuals living with MS face several challenges before, during and after the diagnosis. Participants' stories naturally started with a discussion of the time at which a diagnosis of MS was made. The symptoms of MS are different for every person, depending on the location of the lesions as well as the extent of damage in the CNS (Mozo-Dutton, Simpson \& Boot 2012). Once the symptoms interfered enough with the daily lives of the participants, the process of involving healthcare professionals in finding a diagnosis started. As has been well recognised in the literature (Fernández et al. 2010; Quinn 2011), individuals who suffer from MS often undergo years of frustrating diagnostic assessment before a final diagnosis of MS is reached. Most of the participants in this study describe the process of getting to a diagnosis not only as lengthy, but also as involving extensive emotional turmoil. It was evident that several participants did seek medical help when some of their early symptoms appeared but were only referred to a specialist after numerous visits. This suggests that some general practitioners might have difficulty in recognising the associations between early symptoms. Knowing that prompt intervention may preclude relapse, postponement in the diagnostic process could potentially be problematic. This aspect emphasises that reaching a diagnosis of MS is generally a complicated and lengthy process (Courtney et al. 2009; Reipert 2004).

The vivid recollections and negative accounts of receiving a diagnosis of MS emphasise the immense impact on the participants. Their reactions varied between shock and devastation - however, it was interesting to note that one of the 10 participants reacted positively to the news because she finally knew what was wrong with her. Although in the minority, this type of reaction could potentially be seen as a resource. The reactions found in this study therefore support the mixed reactions to receiving a diagnosis of MS that were reported in previous studies (Barker-Collo et al. 2006; Malcomson et al. 2008). It was evident from this study that coming to terms with the overwhelming news of an MS diagnosis was emotionally challenging for the majority of the participants. This negative experience was enhanced by a lack of support from healthcare professionals.

The provision of quality information and effective communication between healthcare professionals and individuals suffering from a chronic illness has been acknowledged as tremendously important, especially around the time of diagnosis (Barker-Collo et al. 2006); Thorne et al. 2004). It was, however, evident from the findings of this study that a lack of communication between these parties can lead to a negative experience of feeling completely unsupported. The participants voiced their dissatisfaction by describing the interaction with healthcare professionals as unsympathetic, rushed and indifferent. It was also evident that the participants were disappointed with the limited information about MS with which healthcare providers provided them at the time of diagnosis, as this was identified as being a great need at the time. This lack of information and communication contributed considerably to the uncertainty and frustration that had been part of the participants' lives for a long time, starting long before the diagnosis. It would appear, therefore, that the supportive role of the healthcare providers in the South African context with regard to the provision of information and effective communication requires attention.

A further challenge was the wide variety of signs and symptoms that interfered with the participants' daily lives. Impaired mobility, bladder and bowel problems, sexual dysfunction, visual problems, fatigue and the effect of heat were highlighted by the participants as the most challenging. These signs and symptoms were also reported in other literature that focuses on MS (Blaney \& Lowe-Strong 2009; Coenen et al. 2011; DasGupta \& Fowler 2003; Demirkiran et al. 2006; Diamond et al. 2007; Goretti et al. 2009; Grahn et al. 2008; Romberg et al. 2012; Zivadinov et al. 2003). This subtheme reiterates the multidimensionality and complexity of the daily lives of individuals who suffer from MS. These signs and symptoms also confirm the unpredictability of MS and emphasise the unique presentation and experience of every MS sufferer, because the combination and intensity of the different signs and symptoms varied considerably amongst the participants of this study.

The experience of MS as an 'invisible illness' was described as a major challenge by most of the participants, because it made them feel as if people around them think that they are pretending to be ill. More importantly, this theme emphasises the general public's lack of understanding of MS. In addition, it highlights the need to create awareness about MS amongst the general public. It is possible that this experience is unique to individuals who suffer from MS in South Africa, because no study could be found where MS patients shared similar experiences. It is, however, interesting to note that the participants of a qualitative study on the experience of the spouses of MS patients referred to the 'invisible symptoms' of MS (Courts, Newton \& McNeal 2005). This was based on remarks by friends that the MS patient does not appear to be sick.

Finally, a challenge related to medical aid schemes emerged from the data analysis. Several participants reported how they needed to experience at least two relapses in two years before their medical aid scheme would consider paying for their treatment, such as chronic medication. This was seen as a challenge, firstly, because they had to wait for a relapse before being considered for financial assistance. Secondly, this brought about financial difficulties, because whilst the medical aid scheme does not pay for their treatment, which is extremely expensive, they need to finance it themselves. Alternatively, patients can make use of state facilities for some of their chronic medication, but this is not ideal as state facilities do not always have access to the specific medication that they need. Challenges with access to medical services are not unique to South Africa and reiterate the challenges 
that have been found elsewhere. A recent study in Australia echoes the high cost of medical services and emphasises that multi-provider care needs to be more accessible to individuals with chronic illnesses (Yen et al. 2010).

In addition to the challenges faced by the participants in this study, several resources were identified that the participants regarded to be important in order for them to cope with MS. The first resource was social support from various sources with the most important being support from family and friends, as well as support coming from MS support groups. Perceived social support has been found to be a major resource for participants and critical for coping with the challenges of MS in various studies (Coenen et al. 2011; Goretti et al. 2009; Lode et al. 2007; Malcomson et al. 2008; Mohr et al. 1999). This study confirms the value of having a good social support system.

Furthermore, participants seem to find the online MSFacebook support group particularly helpful. Various advantages of online support groups have been identified. These groups are not subject to spatial, geographic and temporal constraints; participants can thus send or receive messages at any time of the day (Coulson, Buchanan \& Aubeeluck 2007). The individual is able to consider the content of their message and formulate it at their own pace prior to posting it (Coulson et al. 2007). Online support groups afford the individual more anonymity than face-to-face support groups; this could make the process of self-disclosure easier and also assist the individual in offering their opinion without the fear of worry or embarrassment that might be present in a face-toface support group (Coulson 2005; Coulson \& Knibb 2007; Winzelberg et al. 2003). Furthermore, there is no status within online support groups, in that all individuals are considered equal regardless of their wealth, class, race and occupation; this allows all members to feel empowerment and equality (Barak, Boniel-Nissim \& Suler 2008). There seems to be a lack of research on the use of online support groups by MS patients. The literature contains many studies on the use of online support groups for more well-known illnesses, such as cancer or arthritis (Coulson et al. 2007), whereas no studies could be found that focused on online support groups for MS patients.

Another important resource for the participants was mobility aids, including their walking aids such as crutches, wheelchairs and hoists to get in and out of the bed. Mobility aids as a resource have not been mentioned explicitly in other research as being a support for individuals, however Finlayson, Garcia and Cho (2008) report that occupational therapists are needed in order to help select and train individuals with MS in the use of their walking aids. These authors also reported that, from their study in which 1274 participants were questioned about whether they experience mobility as a problem, 58\% responded that their immobility interfered a great deal with their daily living (Finlayson et al. 2008). It is clear that mobility aids can make a substantial difference in the lives of individuals with MS.
Religion has also been identified as a major resource by a number of participants in this study. The literature consistently indicates a positive association between spiritual well-being and overall adjustment, hopefulness and quality of life in individuals with chronic illnesses, including MS (Makros \& McCabe 2003; McNulty, Livneh \& Wilson 2004). More specifically, religion has been shown to play an important role in the lives of individuals with chronic medical conditions and to provide emotional support, purpose and meaning in their lives (Arzouman et al. 1991; Hall 1998; Twork et al. 2007). It has been found that a number of indicators of religion, such as having a relationship with God, frequency of prayer and church membership are related positively to measures of life satisfaction, happiness, wellbeing and low psychological distress (Arzouman et al. 1991); Levin \& Taylor 1998). Reports by several participants of the current study support the findings in existing literature that individuals suffering from a chronic illness find their religion to be an important coping mechanism and source of emotional support. It is evident in the findings of this study that positive religious ways of coping, such as seeking spiritual support from their church, being part of a religious community and regular prayers, had given them hope and encouragement in their dealings with MS. Some also used their religion to place a positive interpretation on their diagnosis. One possible explanation for this could be that religion may give these individuals a sense of meaning with regard to what is happening in their lives.

Corresponding with other findings (Courts et al. 2005; Thorne et al. 2004), all of the participants in this study stressed the desire and need for quality information about MS. Knowledge was gained from various sources, such as reading autobiographies of individuals with MS, exchanging information in support groups, or gathering more medical information regarding their disease via the Internet. Information or knowledge was seen as being empowering; it helped individuals to understand their condition and helped them to take control of their situation. Knowledge and information about MS can also play an important role in modifying fear regarding this condition (Thorne et al. 2004). Knowledge about MS is generally seen as being empowering, whether it comes from the internet, books, support groups, MS courses, MS nurses or friends and family (Kirkpatrick Pinson, Ottens \& Fisher 2009; Malcomson et al. 2008). The literature suggests that healthcare professionals could play an important role in providing individuals who suffer from MS with quality information, not only at the time of diagnosis, but throughout the progression of the disease (Thorne et al. 2004). However, none of the participants in this study reported that their healthcare professional provided them with useful information, neither at the time of diagnosis nor during the progression of the disease. Sufficient information, once the diagnosis was received, could lead individuals with MS to using more effective coping styles such as planning and seeking social support (Lode et al. 2007). On the other hand, participants who felt dissatisfied with the information from their doctor tended to use less-effective coping styles such as avoidance and denial (Lode et al. 2007).This highlights 
the importance of quality information from various sources, including healthcare professionals.

\section{Conclusion}

MS is a debilitating condition which affects every aspect of an individual's life - social, emotional and physical. The aim of this study was to contribute to the existing literature on the experiences of individuals living with MS. In addition, this study aimed to explore the unique experiences of individuals living with MS within the South African context, with a specific focus on the challenges faced by these individuals and the support and/or resources that help them to cope with their condition. Many of the challenges that are faced by the participants of this study, such as the lengthy and complicated process of diagnosis, the emotional turmoil around this process and the variety of symptoms that interfere with their daily functioning, are similar to challenges experienced worldwide by individuals who suffer from MS. However, there seems to be considerable scope for improving the quality of information provided by and the communication between the healthcare professionals and individuals who suffer from MS within the South African context.

Furthermore, this study seems to be the first to identify MS as an 'invisible illness'. This emphasises the importance of psycho-education and creating awareness about MS amongst the general public of South Africa. Although not unique to South Africa, the findings seem to suggest that the medical support in the South African context, whether from a medical aid scheme or from public hospitals, is unsatisfactory and problematic. On the other hand, most of the resources that have been identified in this study, such as support by family and friends, religion and knowledge about MS, are comparable to sources of support identified in previous literature. However, mobility aids, identified as a major resource in this study, have not been identified explicitly as a resource amongst MS patients in existing literature. Furthermore, the online MS Facebook support group emerged as a major source of support for the participants of this study. This seems to be a form of support that is unique to the South African context. It is, however, possible that this is a fairly new form of support and would thus explain the paucity of research in this regard.

\section{Limitations}

The current study comprised a convenience sample of individuals with MS residing in the Western Cape. Consequently, the findings of the study cannot be generalised to the broader group of individuals with MS in South Africa. Generalising the results of the current study, for example, to individuals with relatively-low levels of formal education or from particularly deprived socio-economic backgrounds would be inappropriate. Another limitation relates to the accounts of the participants regarding the process of diagnosis. It is possible that their accounts may be inaccurate as, for some, this occurred several years prior to the interview.
Participants may have remembered their encounters with the medical staff and their reactions in response to the diagnosis differently to how they actually were. However, the literature highlighted this as an important aspect of living with MS and it emerged as an important theme during the data analysis. It was therefore included in the investigation.

\section{Recommendations for further study}

As with most exploratory studies, the value of the current study appears to be that it has taken the first step in attempting to understand the nature of the experience of individuals with MS within the South African context. It shows that although individuals with MS face several challenges, these individuals also make use of numerous resources which help them to cope with this debilitating neurological condition. The findings of this study can contribute to creating awareness about the experience of individuals living with MS and to the development of interventions which are tailormade for this unique group of individuals. Given that this was a qualitative study involving an in-depth investigation of the experiences of a small group of individuals with MS, it may be worthwhile replicating this study with a more representative sample before making recommendations for practice. More specifically, there would be value in replicating this study with samples from the broader South African arena and with samples stratified with regard to gender, ethnicity, socio-economic status and education.

\section{Acknowledgements}

This work is based on research which was supported by the National Research Foundation (NRF).

\section{Competing interests}

The authors declare that they have no financial or personal relationship(s) which may have inappropriately influenced them in writing this article.

\section{Authors' contributions}

C.P. (Stellenbosch University) was the project leader, was responsible for supervision and wrote part of the manuscript. N.J. (Stellenbosch University), a student who worked under the supervision of the project leader, was involved in the data collection, data analysis and wrote part of the manuscript.

\section{References}

Arzouman, J.M., Dudas, S., Ferrans, C.E. \& Holm, K., 1991, 'Quality of life of patients with sarcoma postchemotherapy', Oncology Nursing Forum 18(5), 889-894.

Barak, A., Boniel-Nissim, M. \& Suler, J., 2008, 'Fostering empowerment in online support groups', Computers in Human Behavior 24(5), 1867-1883. http://dx.doi. org/10.1016/j.chb.2008.02.004

Barker-Collo, S., Cartwright, C. \& Read, J., 2006, 'Into the unknown: the experiences of individuals living with multiple sclerosis', Journal of Neuroscience Nursing 38(6), 435-441, 446. http://dx.doi.org/10.1097/01376517-200612000-00008

Bhigjee, A.I., Moodley, K. \& Ramkissoon, K., 2007, 'Multiple sclerosis in KwaZulu Natal, South Africa: an epidemiological and clinical study', Multiple Sclerosis 13(9), 1095-1099. http://dx.doi.org/10.1177/1352458507079274

Blaney, B.E. \& Lowe-Strong, A., 2009, 'The impact of fatigue on communication in multiple sclerosis. The insider's perspective', Disability and Rehabilitation 31(3), 170-180. http://dx.doi.org/10.1080/09638280701869629

Braun, V. \& Clarke, V., 2006, 'Using thematic analysis in psychology', Qualitative Research in Psychology 3(2), 77-101. http://dx.doi.org/10.1191/1478088706qp063oa 
CBC News, 2012, MS rates around the world, viewed 15 December 2012, from http:// www.cbc.ca/news/interactives/map-ms/

Coenen, M., Basedow-Rajwich, B., König, N., Kesselring, J. \& Cieza, A., 2011, 'Functioning and disability in multiple sclerosis from the patient perspective', Chronic Illness 7(4), 291-310. http://dx.doi.org/10.1177/1742395311410613

Coulson, N.S., 2005, 'Receiving social support online: an analysis of a computermediated support group for individuals living with irritable bowel syndrome Cyberpsychology \& Behavior 8(6), 580-584. http://dx.doi.org/10.1089/ cpb.2005.8.580

Coulson, N.S., Buchanan, H. \& Aubeeluck, A., 2007, 'Social support in cyberspace: a content analysis of communication within a Huntington's disease online support group', Patient Education and Counseling 68(2), 173-178. http://dx.doi. org/10.1016/j.pec.2007.06.002

Coulson, N.S. \& Knibb, R.C., 2007, 'Coping with food allergy: exploring the role of the online support group', Cyberpsychology \& Behavior 10(1), 145-148. http://dx.doi. org/10.1089/cpb.2006.9978

Courtney, A.M., Treadaway, K., Remington, G. \& Frohman, E., 2009, 'Multiple sclerosis', Medical Clinics of North America 93(2), 451-476. http://dx.doi.org/10.1016/j. mcna.2008.09.014

Courts, N.F., Newton, A.N. \& NcNeal, L.J., 2005, 'Husbands and wives living with multiple sclerosis', Journal of Neuroscience Nursing 37(1), 20-27. http://dx.doi. multiple sclerosis', Journal of Neuroscience
org/10.1097/01376517-200502000-00004

Crabtree, B.F. \& Miller, W.L., 1999, Doing qualitative research, 2nd edn., Sage, Thousand Oaks, CA.

Cross, A.H., Cross, K.A. \& Piccio, L., 2012, 'Update on multiple sclerosis, its diagnosis and treatments', Clinical Chemistry and Laboratory Medicine 50(7), 1203-1210. http://dx.doi.org/10.1515/cclm-2011-0736

DasGupta, R. \& Fowler, C.J., 2003, 'Bladder, bowel and sexual dysfunction in multiple sclerosis: management strategies', Drugs 63(2), 153-166. http://dx.doi. org/10.2165/00003495-200363020-00003

Demirkiran, M., Sarica, Y., Uguz, S., Yerdelen, D. \& Aslan K., 2006, 'Multiple sclerosis patients with and without sexual dysfunction: are there any differences?', Multiple Sclerosis 12(2), 209-214. http://dx.doi.org/10.1191/135248506ms1253oa

Diamond, B.J., Johnson, S.K., Kaufman, M. \& Graves, L., 2007, 'Relationships between information processing, depression, fatigue and cognition in multiple sclerosis' Archives of Clinical Neuropsychology 23(2), 189-199. http://dx.doi.org/10.1016/j acn.2007.10.002

Dua, T. \& Rompani, P., 2008, Atlas: Multiple sclerosis resources in the world 2008 viewed 15 December 2012, from http://www.who.int/mental_health/neurology/ Atlas_MS_WEB.pdf

Fernández, O., Fernández, V., Arbizu, T., Izquierdo, G., Bosca, I., Arroyo, R. et al., 2010 'Characteristics of multiple sclerosis at onset and delay of diagnosis and treatment in Spain (the Novo Study)', Journal of Neurology 257(9), 1500-1507. http://dx.doi. in Spain (the Novo Study)', Journal
org/10.1007/s00415-010-5560-1

Finlayson, M., Garcia, J.D. \& Cho, C., 2008, 'Occupational therapy service use among people aging with multiple sclerosis', American Journal of Occupational Therapy 62(3), 320-328. http://dx.doi.org/10.5014/ajot.62.3.320

Goretti, B., Portaccio, E., Zipoli, V., Hakiki, B., Siracusa, G., Sorbi, S. et al., 2009, 'Coping strategies, psychological variables and their relationship with quality of life in multiple sclerosis', Neurological Sciences 30(1), 15-20. http://dx.doi.org/10.1007/ s10072-008-0009-3

Grahn, D.A., Murray, J.V. \& Heller, C.G., 2008, 'Cooling via one hand improves physical performance in heat-sensitive individuals with multiple sclerosis: a preliminary study', BMC Neurology 8, 14. http://dx.doi.org/10.1186/1471-2377-8-14

Hall, B.A., 1998, 'Patterns of spirituality in persons with advanced HIV disease' Research in Nursing \& Health 21(2), 143-153. http://dx.doi.org/10.1002/ (SICI)1098-240X(199804)21:2<143::AID-NUR5>3.0.CO;2-J

Jeffrey, S., 2010, Fingolimod receives FDA approval as first oral MS treatment, viewed 16 December 2012, from http://www.medscape.com/viewarticle/729172

Kirkpatrick Pinson, D.M., Ottens, A.J. \& Fisher, T.A., 2009, 'Women coping successfully with multiple sclerosis and the precursors of change', Qualitative Health Research 19(2), 181-193. http://dx.doi.org/10.1177/1049732308329465

Kraft, G.H., 2010, 'Beat the heat', Momentum 3(3), 46.

Levin, J.S. \& Taylor, R.J., 1998, 'Panel analyses of religious involvement and well-being in African Americans: contemporaneous vs. longitudinal effects', Journal for the Scientific Study of Religion 37(4), 695-709. http://dx.doi.org/10.2307/1388151

Lincoln, Y.S. \& Guba, E.A., 1985, Naturalistic inquiry, Sage, Beverly Hills, CA.

Lode, K., Larsen, J.P., Bru, E., Klevan, G., Myhr, K.M. \& Nyland, H., 2007, 'Patient information and coping styles in multiple sclerosis', Multiple Sclerosis 13(6), 792799. http://dx.doi.org/10.1177/1352458506073482

Malcomson, K.S., Lowe-Strong, A.S. \& Dunwoody, L., 2008, 'What can we learn from the personal insights of individuals living and coping with multiple sclerosis?', Disability and Rehabilitation 30(9), 662-674. http://dx.doi. org/10.1080/09638280701400730

Maghzi, A.H., Borazanci, A., McGee, J., Alexander, J.S., Gonzalez-Toledo, E. \& Minagar A., 2011, 'Multiple sclerosis: pathophysiology, clinical features, diagnosis, and management', in A. Minagar (ed.), Neuroinflammation, pp. 1-23, London, Elsevier. http://dx.doi.org/10.1016/B978-0-12-384913-7.00001-0
Marino, F.E., 2009, 'Heat reactions in multiple sclerosis: an overlooked paradigm in the study of comparative fatigue', International Journal of Hyperthermia 25(1) 34-40. http://dx.doi.org/10.1080/02656730802294020

Makros, J. \& McCabe, M., 2003, 'The relationship between religion, spirituality, psychological adjustment, and quality of life among people with multiple sclerosis', Journal of Religion and Health 42(2), 143-159. http://dx.doi. org/10.1023/A:1023681830716

Matuska, K., Mathiowetz, V. \& Finlayson, M., 2007, 'Use and perceived effectiveness of energy conservation strategies for managing multiple sclerosis fatigue', American Journal of Occupational Therapy 61(1), 62-69. http://dx.doi.org/10.5014/ ajot.61.1.62

McCabe, N.P., 2005, 'Mood and self-esteem of persons with multiple sclerosis following an exacerbation' Journal of Psychosomatic Research 59(3), 161-166. http://dx.doi.org/10.1016/j.jpsychores.2005.04.010

McDonald, W.I., Compston, A., Edan, G., Goodkin, D., Hartung, H.P., Lublin, F.D. et al., 2001, 'Recommended diagnostic criteria for multiple sclerosis: guidelines from the International Panel on the diagnosis of multiple sclerosis', Annals of Neurology 50(1), 121-127. http://dx.doi.org/10.1002/ana.1032

McNulty, K., Livneh, H.L. \& Wilson, L.M., 2004, 'Perceived uncertainty, spiritual well-being, and psychosocial adaptation in individuals with multiple sclerosis', Rehabilitation Psychology 49(2), 91-99. http://dx.doi.org/10.1037/0090 5550.49.2.91

Modi, G., Mochan, A., Du Toit, M. \& Stander, I., 2008, 'Multiple sclerosis in South Africa', South African Medical Journal 98(5), 391-393.

Mohr, D.C., Dick, L.P., Russo, D., Pinn, J., Boudewyn, A.C., Likosky, W., et al. 1999, 'The psychosocial impact of multiple sclerosis: exploring the patient's 1999, 'The psychosocial impact of multiple sclerosis: exploring the patient's
perspective', Health Psychology 18(4), 376-382. http://dx.doi.org/10.1037/0278perspective', 6133.18 .4 .376

Mozo-Dutton, L., Simpson, J. \& Boot, J., 2012, 'MS and me: exploring the impact of multiple sclerosis on perceptions of self', Disability and Rehabilitation 34(14) 1208-1217. http://dx.doi.org/10.3109/09638288.2011.638032

Payne, D. \& McPherson, K.M., 2010, 'Becoming mothers. Multiple sclerosis and motherhood: a qualitative study', Disability and Rehabilitation 32(8), 629-638. http://dx.doi.org/10.3109/09638280903204708

Prunty, M., Sharpe, L., Butow, P. \& Fulcher, G., 2008, 'The motherhood choice: themes arising in the decision-making process for women with multiple sclerosis Multiple Sclerosis 14(5), 701-704. http://dx.doi.org/10.1177/1352458507086103

Quinn, C., 2011, 'A major brainwave', Nursing Standard 25(22), 24-25.

Reipert, B., 2004, 'Multiple sclerosis: a short review of the disease and its differences between men and women', Journal of Men's Health \& Gender 1(4), 334-340. http://dx.doi.org/10.1016/j.jmhg.2004.10.005

Riise, T., Mohr, D.C., Munger, K.L., Rich-Edwards, J.W., Kawachi, I. \& Ascherio, A., 2011 'Stress and the risk of multiple sclerosis', Neurology 76(22), 1866-1871. http:// dx.doi.org/10.1212/WNL.0b013e31821d74c5

Robinson, R., 2011, 'Revised McDonald criteria make MS diagnosis simpler, faster', Neurology Today 11(8), 36-38. http://dx.doi.org/10.1097/01. NT.0000397965.95998.00

Romberg, A., Ikonen, A., Ruutianen, J., Virtanen, A. \& Hämäläinen, P., 2012, 'The effects of heat stress on physical functioning in persons with multiple sclerosis', Journal of the Neurological Sciences 319(1-2), 42-46. http://dx.doi.org/10.1016/j. jns.2012.05.024

Rumrill, P.D., 2009, 'Multiple sclerosis: medical and psychosocial aspects, etiology incidence and prevalence', Journal of Vocational Rehabilitation 31(2), 75-82.

Saaroni, H., Sigal, A., Lejbkowicz, I. \& Miller, A., 2010, 'Mediterranean weather conditions and exacerbations of multiple sclerosis', Neuroepidemiology 35(2), 142-151. http://dx.doi.org/10.1159/000313446

Tataru, N., Vidal, C., Decavel, P., Berger, E. \& Rumbach, L., 2006, 'Limited impact of the summer heat wave in France (2003) on hospital admissions and relapses for multiple sclerosis', Neuroepidemiology 27(1), 28-32. http://dx.doi. org/10.1159/000094233

Thorne, S., Con, A., McGuinness, L., McPherson, G. \& Harris, S.R., 2004, 'Health care communication issues in multiple sclerosis: an interpretive description', Qualitative Health Research 14(1), 5-22. http://dx.doi.org/10.1177/1049732303259618

Twork, S., Wirtz, M., Schipper, S., Klewer, J., Bergmann, A. \& Kugler, J., 2007, 'Chronical illness and maternity: life conditions, quality of life and coping in women with multiple sclerosis', Quality of Life Research 16(10), 1587-1594. http://dx.doi. multiple sclerosis', Quality of
org/10.1007/s11136-007-9268-3

Winzelberg, A.J., Classen, C., Alpers, G.W., Roberts, H., Koopman, C., Adams, R.E. et al., 2003, 'Evaluation of an internet support group for women with primary breast cancer', Cancer 97(5), 1164-1173. http://dx.doi.org/10.1002/cncr.11174

Yen, L., Gillespie, J., Jeon, Y.H., Kljakovic, M., Brien, J., Jan, S. et al., 2010, 'Health professionals, patients and chronic illness policy: a qualitative study', Health Expectations 14(1), 10-20. http://dx.doi.org/10.1111/j.1369-7625.2010.00604.x

Young, C.A., 2011, 'Factors predisposing to the development of multiple sclerosis', QJM 104(5), 383-386. http://dx.doi.org/10.1093/qjmed/hcr012

Zivadinov, R., Zorzon, M., Locatelli, L., Stival, B., Monti, F., Nasuelli, D. et al., 2003 'Sexual dysfunction in multiple sclerosis: a MRI, neurophysiological and urodynamic study', Journal of the Neurological Sciences 210(1-2), 73-76. http:// dx.doi.org/10.1016/S0022-510X(03)00025-X 